\title{
Potentialities of Digital Capillaroscopy in the Diagnostics of Oedema Syndrome
}

\author{
Yury I. Gurfinkel ${ }^{1 *}$, and Maria L. Sasonko ${ }^{2}$ \\ ${ }^{1}$ Laboratory of blood microcirculation, Medical Research and Educational Center, Lomonosov Moscow State \\ University, Moscow, Russia \\ ${ }^{2}$ Research Clinical Centre, JSC Russian Railways, Moscow, Russia \\ * e-mail: yugurf@yandex.ru
}

\begin{abstract}
The paper is devoted to the study of digital capillaroscopy potentialities in the assessment of oedema syndrome by the example of a group of patients with diseases of cardiovascular system (CVS). 75 patients were examined, 47 of them with CVS diseases and 28 healthy volunteers. Alongside with the standard examination customary for this pathology, the capillaroscopy of hand finger nail bed was carried out in all patients. The study has revealed considerable dilation of transitional segments of capillaries, increase of the capillary bed remodelling coefficient and the linear dimension of perivascular zone in patients with clinically expressed oedema syndrome. In the group of patients with CVS diseases without clinically expressed oedema, we revealed the statistically significant increase of perivascular zones and remodelling coefficient of capillary bed. The digital optical capillaroscopy can be applied in the clinical practice for early diagnostics of the hidden oedema syndrome and as a quantitative method of diagnostics for clinically expressed oedema and assessment of drug therapy efficiency. (C) 2017 Journal of Biomedical Photonics \& Engineering.
\end{abstract}

Keywords: digital capillaroscopy; oedema syndrome; remodelling coefficient; perivascular zone.

Paper \#3218 received 13 Jan 2017; revised manuscript received 13 Mar 2017; accepted for publication 15 Jun 2017; published online 7 Jul 2017. doi: 10.18287/JBPE17.03.030401. [Special Issue. Years in Biophotonics: 70th Anniversary of Prof. A.V. Priezzhev].

\section{References}

1. G. Yu. Suvorova, and A. I. Martynov, Oedema syndrome: clinical presentation, differential diagnostics, treatment, GEOTARMedia, Moscow, Russia (2009) [in Russian].

2. V. Yu. Mareyev, M. O. Danielyan, Yu. N. Belenkov, et al, "Epidemiologic examination of patients with CHI in real practice (by medical aid appealability)," EPOKhA-O-KhSN study, Serdechnaya nedostatochnost' 4(3), 116-120 (2003) [in Russian].

3. P. Ponikowski et al., "ESC Guidelines for the diagnosis and treatment of acute and chronic heart failure," European Journal of Heart Failure 18, 891-975 (2016).

4. A. J. Houben, J. H. Beljaars, L. Hofstra, A. A. Kroon, and P. W. de Leeuw, "Microvascular Abnormalities in Chronic Heart Failure: A Cross-Sectional Analysis," Microcirculation 10(6), 471-478 (2003).

5. Yu. I. Gurfinkel', O. V. Makeyeva, and V. A. Ostrozhinskii, "Peculiarities of microcirculation, endothelial function, and the pulse wave propagation velocity in patients with initial stages of arterial hypertension," Funktsional'naya diagnostika 2, 18-25 (2010) [in Russian].

6. Yu. I. Gurfinkel', O. Yu. At'kov, M. L. Sasonko, and R. M. Sarimov, "New approach to the integral assessment of the cardiovascular system condition in patients with arterial hypertension," Rossiyskii kardiologicheskii zhurnal 105(1), 101-106 (2014). 


\section{Introduction}

The oedema syndrome is a combination of signs characterising the retention of liquid in the organism with its predominant accumulation in tissues. It is most clearly manifested by peripheral oedema [1]. The oedema syndrome is often met in clinical practice, particularly, in patients of elder age groups. Frequently the patient seeks medical attention with the main complaint of oedema appearance, and exactly at this moment, it is important to estimate correctly the character and the degree of expression of the oedema syndrome.

The most frequent cause of oedema syndrome development in elderly persons is the heart failure (HF) as an outcome of different diseases of cardiovascular system (CVS), such as the arterial hypertension, coronary heart disease, etc. In European countries, the HF occurrence amounts to $2-4 \%$ of the population. In Russia, the HF occurrence amounts to $7 \%$ of the population [2]. The absence of specific symptoms and objective signs of the disease may complicate the diagnostics of CHI. However, according to the documents of the European Society of Cardiology, insignificant or moderate manifestations of $\mathrm{HF}$ are fraught with serious risk of hospitalisation and death, which makes it necessary to seek for new diagnostic possibilities of objective assessment of the patient's condition [3].

The cardiovascular diseases (CVDs) are known to affect the microcirculatory bed essentially. As shown by the study of the capillary network density, the diameter and morphology of microvessels of bulbar conjunctiva and finger nail bed in patients with HF, carried out in the Netherlands, the significant impairment of capillary bed parameters accompanies the HF, its expression being the greater the more severe the illness is [4]. At the same time, it is worth noting that the procedure of oedema syndrome diagnostics by general practitioners has not been essentially improved during long time and in most cases is descriptive rather than quantitative.

The aim of the study is to analyse the potentialities of the digital optical capillaroscopy in the diagnostics of oedema syndrome in patients with the diseases of cardiovascular system.

\section{Patients and methods}

The study was performed in 75 persons, including 47 patients and 28 healthy volunteers. The examined patients suffered from arterial hypertension, coronary heart disease, including patients with myocardial infarction in history. The exclusion criteria were the presence of chronical varix dilatation, oncologic diseases, system diseases of connective tissue, hepatic and renal insufficiency, pregnancy and lactation.

The first group consisted of 19 patients (mean age $54.3 \pm 10.5$ years old) having no clinically expressed oedema syndrome (Table 1). In the patients of this group, we observed insignificant limitation of physical activity, transitory (evening) pastosity of ankles, shins, and feet. The second group included 28 patients (mean age $57.7 \pm 9.4$ years old), in which even minor physical loads led to the appearance of palpitation and dyspnoea. Besides that, they had expressed oedema of ankles, shins, and feet. All patients received combined drug treatment daily (Table 2).

Investigation of blood capillaries and surrounding tissues parameters of the finger nail bed was implemented using the digital capillaroscope ("Kapillaroskan-1", Russia), equipped with high-speed video camera that provided video file recording with the rate of 200 frames per second. The day before the examination, the patients and volunteers did not smoke and did not use caffeine-containing drinks. The examination was carried out in the sitting position after 15-20 minutes of rest under the conditions of constant temperature in the room $\left(22-24^{\circ} \mathrm{C}\right)$, before taking the morning dose of drugs. The capillary blood flow was studied in the eponychium of the fourth or third finger of the left hand. The finger under study was fixed in a special holder with soft pressing of the middle phalange dorsal surface, providing full immobilisation during the examination. The temperature of the nail phalange near the eponychium was measured using the contactless thermometer Ri-thermo N (Riester, USA). With the magnification of $400 \times$, at least $6-10$ video fragments were recorded for further quantitative analysis.

The processing of raw information was implemented using the software that allowed the viewing of the recorded video fragments, the measurement of capillary diameters in the arterial, transitional, and venous segments. The linear size of the perivascular zone was defined as the separation between the most distant point of the perivascular zone and the closest point of the capillary transitional segment.

Table 1 Clinical presentations in the groups of patients with diseases of cardiovascular system.

\begin{tabular}{ll}
\hline Group of patients & Physical activity and clinical presentations \\
\hline $\begin{array}{l}\text { Group } 1 \\
(\mathbf{n}=\mathbf{1 9})\end{array}$ & $\begin{array}{l}\text { Insignificant limitation of physical activity. The physical load can cause fatigability, palpitation, } \\
\text { dyspnoea. Ankle and shin transient pastosity. No oedema in feet, ankles and shins. }\end{array}$ \\
\hline $\begin{array}{l}\text { Group } 2 \\
(\mathbf{n}=\mathbf{2 8})\end{array}$ & $\begin{array}{l}\text { Limitation of physical activity. Insignificant loads lead to palpitation and dyspnoea. Expressed } \\
\text { oedema of feet, ankles and shins }\end{array}$ \\
\hline
\end{tabular}


Table 2 Clinical characterisation of the groups under study.

\begin{tabular}{|c|c|c|}
\hline Parameter & $\begin{array}{l}\text { Control group } \\
(\mathrm{n}=\mathbf{2 8})\end{array}$ & $\begin{array}{l}\text { Patients with } \\
\text { cardiovascular diseases } \\
(n=47)\end{array}$ \\
\hline Age, years & $56.4 \pm 7.5$ & $57.0 \pm 9.1$ \\
\hline Sex, m/f, \% & $74 / 26$ & $79 / 21$ \\
\hline Body mass index, $\mathrm{kg} / \mathrm{m}^{2}$ & $28.4 \pm 5.62$ & $29.2 \pm 7.6$ \\
\hline Smoking, $\%$ & 41 & 34 \\
\hline Ejection fraction, $\%$ & $64.8 \pm 5.2$ & $53.9 \pm 12.1^{*}$ \\
\hline Arterial hypertension, \% & - & 68 \\
\hline Type-2 diabetes, $\%$ & - & 25 \\
\hline Postinfarction cardiosclerosis, $\%$ & - & 41 \\
\hline \multicolumn{3}{|c|}{ Drug therapy, $\%$} \\
\hline$\beta$-blocking agents & - & 58.9 \\
\hline ACE inhibitors / Sartans & - & 88.6 \\
\hline Calcium antagonists & - & 25.9 \\
\hline Diuretics & - & 57.9 \\
\hline Statines & - & 64.4 \\
\hline Nitrates & - & 15.8 \\
\hline
\end{tabular}

Note: The asterisk marks the parameter, for which the difference between the groups is statistically significant.

To estimate the degree of capillary constriction, we used the coefficient of capillary bed remodelling (CCBR), introduced by us earlier as a ratio of the mean capillary diameter in the venous segments and the mean capillary diameter in the arterial segments $[5,6]$.

\subsection{Statistics}

The statistical differences between the groups were determined using the Student criterion. The normality of the parameters distribution was assessed using the Kolmogorov-Smirnov criterion. The plurality of comparison was taken into account by means of the false discovery rate method. The results are presented in the tables as $M \pm m$, where $M$ is the mean value of the parameter and $\mathrm{m}$ is the standard deviation. The statistical analysis was carried out using the standard statistical software package IBM SPSS Statistic 20.

\section{Results}

The basic characterisation of the groups is presented in Table 2. The studied groups are comparable in age, sex and smoking status. The patients had significantly higher body mass index and essentially lower index of global left ventricle myocardial contractility then the healthy volunteers.

The results of comparison of the measured parameters in the group of healthy volunteers and the subgroups of patients with CHI are presented in Table 3.

In comparison with the healthy volunteers, in the patients of the first group we revealed decreased level of systolic and diastolic arterial pressure and pulse rate. The presence of patients with type- 2 diabetes in this group explains the increased blood glucose level. The ejection fraction of the left ventricle stayed within the interval of normal values, but was significantly lower than in the control group. The analysis of the microcirculation parameters revealed the statistically significant increase of perivascular zone size and CCBR.

In the patients of the second group the levels of arterial pressure and pulse rate did not significantly differ from those of healthy volunteers. We noticed the decrease of the global contractility of myocardium. The changes of microcirculation parameters in this group were most strongly expressed. The linear size of the perivascular zone was significantly increased, the mean value of the transitional segment and CCBR were significantly higher than in the group of healthy volunteers. 
Table 3 Distribution of the measured parameters in the groups under study.

\begin{tabular}{|c|c|c|c|c|c|}
\hline \multirow{2}{*}{ Parameter } & \multirow{2}{*}{$\begin{array}{l}\text { Control group } \\
(\mathbf{n}=\mathbf{2 8})\end{array}$} & \multicolumn{4}{|c|}{$\begin{array}{l}\text { Patients with diseases of cardiovascular system } \\
(n=47)\end{array}$} \\
\hline & & $\begin{array}{l}\text { Group } 1 \\
(n=19)\end{array}$ & p-level & $\begin{array}{l}\text { Group } 2 \\
(\mathrm{n}=\mathbf{2 8})\end{array}$ & p-level \\
\hline $\begin{array}{l}\text { SAP, } \\
\text { мм pm.cm. }\end{array}$ & $127.3 \pm 6.3$ & $121.4 \pm 14.3$ & 0.032 & $128.7 \pm 15.4$ & 0.557 \\
\hline $\begin{array}{l}\text { DAP, } \\
\text { MM pm.cm. }\end{array}$ & $78.6 \pm 7.0$ & $76.1 \pm 10.9$ & 0.028 & $80.8 \pm 9.2$ & 0.342 \\
\hline $\begin{array}{l}\text { Pulse, } \\
\text { min }^{-1}\end{array}$ & $71.9 \pm 12.1$ & $67.7 \pm 11.1$ & 0.039 & $72.8 \pm 11.6$ & 0.715 \\
\hline $\mathbf{P Z}, \mu m$ & $101.3 \pm 14.6$ & $109.4 \pm 10.7$ & 0.004 & $151.1 \pm 16.5$ & 0.000 \\
\hline $\mathbf{A S}, \mu m$ & $9.4 \pm 2.2$ & $9.8 \pm 2.4$ & 0.465 & $9.6 \pm 4.5$ & 0.607 \\
\hline $\mathbf{T S}, \mu m$ & $13.5 \pm 3.1$ & $15.2 \pm 4.4$ & 0.117 & $17.5 \pm 4.4$ & 0.001 \\
\hline $\mathbf{V S}, \mu m$ & $12.8 \pm 3.2$ & $13.9 \pm 3.2$ & 0.119 & $15.0 \pm 3.9$ & 0.677 \\
\hline CCBR & $1.33 \pm 0.1$ & $1.44 \pm 0.2$ & 0.035 & $1.51 \pm 0.30$ & 0.031 \\
\hline $\mathbf{E F}, \%$ & $64.8 \pm 5.2$ & $56.4 \pm 8.9$ & 0.001 & $40.2 \pm 10.1$ & 0.000 \\
\hline Creatinine, $\mu \mathrm{mol} / \mathrm{l}$ & $95.1 \pm 16$ & $96.2 \pm 15$ & 0.645 & $124.5 \pm 36$ & 0.000 \\
\hline Urea, $\mathrm{mmol} / \mathrm{l}$ & $5.9 \pm 0.9$ & $7.8 \pm 1.1$ & 0.446 & $7.0 \pm 2.2$ & 0.023 \\
\hline Glucose, $\mathrm{mmol} / \mathrm{l}$ & $5.5 \pm 0.5$ & $6.2 \pm 0.9$ & 0.015 & $5.9 \pm 0.6$ & 0.332 \\
\hline
\end{tabular}

Note: SAP - systolic arterial pressure; DAP - diastolic arterial pressure; EF-ejection fraction; PZ - perivascular zone; AS - arterial segment; TS - transitional segment; VS - venous segment. The comparison was carried out between the groups of patients with the diseases of cardiovascular system and healthy volunteers. In boldface the parameters with statistically significant differences between the groups are given.

\section{Discussion of results}

Until recently, the capillaroscopy of the hand finger nail bed was not used to assess the condition of cardiovascular system in patients with oedema syndrome. The present paper demonstrates the presence of essential changes of microcirculation parameters in the patients with clinically expressed oedema. Considerable increase of the linear size of perivascular zone in the patients with oedema syndrome as compared to the healthy volunteers was found. The increase of the perivascular zone is probably due to the increase of pressure in the transitional segments of the capillaries, leading to the increase of the capillary diameter in these sections and the activation of liquid release into the perivascular space. The increase of the capillary transitional segment size in our study appeared to be characteristic for the patients with more expressed oedema syndrome (the second group). In the patients of the first group (without clinically expressed oedema) the size of perivascular zone also demonstrated statistically significant difference from that in healthy volunteers, i.e., the increase of the linear size of perivascular zones is not a significant quantitative sign of the oedema syndrome only, but also can be revealed in the patients with hidden oedema.

Against the background of drug therapy, the clinical signs of oedema syndrome can essentially regress, which can be quantitatively assessed by capillaroscopy. Fig. 1 presents the capillarogram of the patient U., admitted to the hospital with expressed oedema syndrome.

The capillaroscopy of hand finger nail bed was executed at the third day of the diuretic therapy, against the background of which the clinical compensation of the oedema syndrome was achieved. The perivascular zone size amounted to $118 \mu \mathrm{m}$ (the solid line, A). Simultaneously the second contour of the perivascular zone (dashed line, B) at the distance of $174 \mu \mathrm{m}$ was determined, corresponding to the initial level of the oedema syndrome. Thus, the linear size of the perivascular zone reflects well the condition of the pericapillary oedema. The obtained data can be used for personal quantitative assessment of the oedema syndrome expression, including that against the background of treatment. 


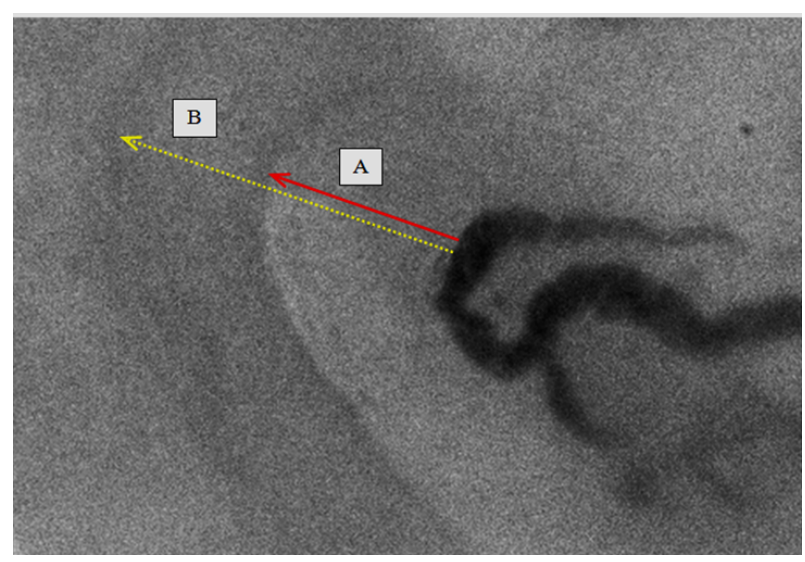

Fig. 1 Dynamics of linear dimension of perivascular zone (PZ) against the background of diuretic therapy. $\mathbf{A}$ - against the background of treatment $(\mathrm{PZ}=118 \mu \mathrm{m})$. $\mathbf{B}-$ before the beginning of treatment $(\mathrm{PZ}=174 \mu \mathrm{m})$.

The increase of the perivascular zone can be revealed not only in the presence of cardiovascular pathology. Clinical observation revealed the oedema of the perivascular tissues of the finger nail bed in the case of receiving a large portion of liquid, salt, alcohol, of chronical venous insufficiency, systemic diseases of the connective tissue. However, the increase of perivascular zone revealed by capillaroscopy is a reason for thorough diagnostic examination of the patients aimed at determining the aetiology and pathogenesis of the oedema syndrome.

\section{Conclusions}

The study has shown the significance of the digital capillaroscopy of hand finger nail bed in the diagnostics of the oedema syndrome. In the patients with oedema syndrome significant deviations of the capillary parameters and surrounding tissues were revealed in comparison with the healthy volunteers.

The increase of the mean diameter of transitional segments of capillaries, the remodelling coefficient and the linear size of perivascular zone in the capillaroscopy of hand finger nail bed are significant markers of the oedema syndrome.

The digital optical capillaroscopy can be applied in the clinical practice for early diagnostics of the hidden oedema syndrome, and as a quantitative diagnostic method for clinically expressed oedema and the efficiency assessment of drug therapy.

\section{Disclosures}

All authors declare that there is no conflict of interests in this paper.

\section{Acknowledgment}

The study was supported by the Russian Scientific Foundation, grant No. 14-15-00602. 